OPEN ACCESS

Approved by:

Frontiers Editorial Office,

Frontiers Media SA, Switzerland

${ }^{*}$ Correspondence: Xiangming Fan fanxiangming@126.com

${ }^{\dagger}$ These authors share first authorship

Specialty section This article was submitted to Computational Physiology and Medicine,

a section of the journal Frontiers in Physiology

Received: 04 March 2020 Accepted: 05 March 2020

Published: 20 March 2020

Citation:

Yang Y, Wang J, Qiao A and Fan X (2020) Corrigendum: Numerical

Simulation of the Influence of Geometric Configurations on Pressure Difference in the Intraventricular Tunnel. Front. Physiol. 11:256 doi: 10.3389/fphys.2020.00256

\section{Corrigendum: Numerical Simulation of the Influence of Geometric Configurations on Pressure Difference in the Intraventricular Tunnel}

\author{
Yao Yang ${ }^{1 \dagger}$, Junjie Wang ${ }^{2+}$, Aike Qiao ${ }^{2}$ and Xiangming Fan ${ }^{1 *}$ \\ ${ }^{1}$ Beijing Anzhen Hospital, Capital Medical University, Beijing, China, ${ }^{2}$ College of Life Sciences and Bioengineering, Beijing \\ University of Technology, Beijing, China
}

Keywords: double outlet right ventricle, intraventricular tunnel, hemodynamics, numerical simulation, surgical planning

\section{A Corrigendum on}

Numerical Simulation of the Influence of Geometric Configurations on Pressure Difference in the Intraventricular Tunnel

by Yang, Y., Wang, J., Qiao, A., and Fan, X. (2020). Front. Physiol. 11:133. doi: $10.3389 /$ fphys.2020.00133

In the original article, the author Xiangming Fan was marked as belonging to affiliation 2. The correct affiliation is 1 . In addition, there was an error in the running title as it referred to "Flow Resistance." The correct running title should be "Simulation of Pressure Difference in the Intraventricular Tunnel."

The authors apologize for this error and state that this does not change the scientific conclusions of the article in any way. The original article has been updated.

Copyright $\odot 2020$ Yang, Wang, Qiao and Fan. This is an open-access article distributed under the terms of the Creative Commons Attribution License (CC BY). The use, distribution or reproduction in other forums is permitted, provided the original author(s) and the copyright owner(s) are credited and that the original publication in this journal is cited, in accordance with accepted academic practice. No use, distribution or reproduction is permitted which does not comply with these terms. 